\title{
The Relation of ABO Blood Group to the Severity of Coronavirus Disease: A Cross-Sectional Study From a Tertiary Care Hospital in Karachi
}

Fazal U. Rehman ${ }^{1}$, Syed Furrukh Omair ${ }^{2}$, Fatima Memon ${ }^{3}$, Bakhtawar J. Rind ${ }^{4,5}$, Danish Ahmed Memon 6 , Syed Ahsan Ali ${ }^{7}$, Bilal Ahmed ${ }^{1}$, Naureen Ali ${ }^{8}$

1. Medicine, The Aga Khan University Hospital, Karachi, PAK 2. Nephrology, The Aga Khan University Hospital, Karachi, PAK 3. Internal Medicine, Dr Ruth Pfau Civil Hospital, Karachi, PAK 4. Family Medicine, The Aga Khan University Hospital, Karachi, PAK 5. Medicine, Jam Ghulam Qadir Civil Hospital Hub, Quetta, PAK 6. Acute Medicine, Russells Hall Hospital, Dudley, GBR 7. Internal Medicine, The Aga Khan University Hospital, Karachi, PAK 8. School of Nursing and Midwifery Department, The Aga Khan University Hospital, Karachi, PAK

Corresponding author: Fazal U. Rehman, fazal.rehman@aku.edu

\section{Abstract}

\section{Background}

Blood groups are considered to have an impact on the occurrence and severity of coronavirus disease. While among Chinese and Caucasian, blood group O individuals were less and group A were more likely to have severe disease and mortality, data on South Asians aren't available.

\section{Objective}

This study aimed to find out the association of disease severity with blood group among coronavirus disease 2019 (COVID-19) patients.

\section{Materials and methodology}

Data were collected on a predesigned questionnaire containing details of patient demographics, medical comorbidities, clinical presentation, and laboratory parameters. Multiple logistic regression was used to determine the association of the blood group with the severity of coronavirus disease.

\section{Result}

Among the study participants, blood group B has the highest distribution (39.8\%), followed by O (30.0), A (21.9\%), and $\mathrm{AB}(8.1 \%)$. About three-fourths (69.9\%) had mild to moderate disease while $30.0 \%$ had severe disease. Age, gender, hypertension, diabetes mellitus, and hemoglobin level were all associated with disease severity among COVID-19 patients in univariate analysis on P-value for selection $(<0.25)$. The final model showed that the odds of disease severity is 3.62 times higher among males (OR: 3.62, 95\% CI: 2.15-6.08) and 2.00 times higher among diabetic patients (OR: $2.00,95 \% \mathrm{CI}: 1.10-3.01$ ) as compared to female and non-

Review began 06/26/2021 Review ended 07/15/2021 Published 07/23/2021

\section{() Copyright 2021}

Rehman et al. This is an open access article distributed under the terms of the Creative Commons Attribution License CC-BY 4.0., which permits unrestricted use, distribution, and reproduction in any medium, provided the original author and source are credited. diabetic respectively. However, there was no significant association found between blood group and disease severity.

\section{Conclusion}

Blood groups don't have any role in forecasting the severity of coronavirus disease. However, the male gender and diabetics are prone to have severe disease.

Categories: Infectious Disease, Hematology

Keywords: disease severity, male gender, diabetes, covid-19, abo blood group

\section{Introduction}

On 31st December 2019, 27 cases of pneumonia of unidentified etiology were documented in Wuhan City, Hubei province in China [1]. The causative agent was recognized from throat swab samples conducted by the Chinese Centre for Disease Control and Prevention (CCDC) on 7th January 2020 and was later named severe acute respiratory syndrome coronavirus 2 (SARS-CoV-2). The disease was titled COVID-19 by the World Health Organization (WHO) [2]. The novel coronavirus SARS-CoV-2, causing the novel coronavirus disease2019 (COVID-19), is currently spreading briskly worldwide; it has been recently declared as a pandemic by WHO. Recent clinical observation advocates that patient age, male sex, and certain chronic medical conditions (e.g., cardiovascular disease, diabetes, chronic obstructive pulmonary disease) appear to represent a risk for the infection of SARS-Cov-2 and higher disease severity [3].

Evidence shows that blood groups have an impact on the occurrence and severity of coronavirus disease 
2019 (COVID-19). The vulnerability to viral infections has been previously found to be related to the ABO blood group. For example, the Norwalk virus and Hepatitis B have clear blood group vulnerability [4,5]. It was also reported that blood group $\mathrm{O}$ individuals were less likely to become infected by SARS coronavirus [6]. Increased disease severity and high mortality are due to increased cardiovascular events in patients with type A blood group and the fewer cardiovascular events in the type O blood group [7].

There is no literature relating blood groups with the predisposition and severity of COVID-19 from this part of the world. Hence, this study is intended to study the relationship between the ABO blood types and COVID-19 disease severity.

\section{Materials And Methods}

The study was designed based on the strobe guidelines. We conducted a retrospective study in tertiary care hospital Karachi, data were collected from the in-patient's medical record after obtaining permission from the institutional ethical review committee of Aga Khan University Hospital (ERC\#2020-5277-11810). All adult patients (aged $>18$ years) diagnosed with COVID-19 using a nasopharyngeal swab run by PCR technique, with a known blood group, were included in the study. While, COVID-19 cases with superimposed bacterial infections elicited by high pro-calcitonin levels, positive blood cultures, or labeled as having bacterial infection by a consultant physician were excluded from the study. No patient identifiers were recorded to protect patient's privacy. A structured questionnaire was designed to collect information regarding patient demographics, comorbid conditions, clinical presentation, disease severity, and laboratory parameter. Disease severity was characterized as per World Health Organization into non-severe, severe, and critical disease [8].

Trained research staff collected the data based on the inclusion criteria and completed all patients' information on pre-designed performa. A total of 369 patients of COVID-19 with known blood groups were included within the period of three months (1st April-30th June 2020).

\section{Results}

Our study included 369 patients of COVID-19, of which $57.4 \%$ ( $n=212$ ) were male and remaining $42.5 \%$ ( $=$ 157 ) were females. The mean $( \pm \mathrm{SD}$ ) age in years of the study participant was $52.8 \pm 17.7$. Almost $30.0 \%$ of patients have greater disease severity while $69.9 \%$ have a non-severe disease. Blood group B has the highest distribution (39.8\%) among COVID-19 infected patients followed by O (30.0), A (21.9\%), and AB (8.1\%). Besides, the prevalence of other comorbidities, documenting hypertension as $38.7 \%$, diabetes mellitus as $36.8 \%$, ischemic heart disease as $15.1 \%$, lung disease as $5.6 \%$, and chronic kidney disease as $10.0 \%$ (Table 1 ). 


\section{Cureus}

\section{Characteristics}

n (\%)

Age (years), mean $\pm S D$

$52.8 \pm 17.7$

Gender

Males

Females

$212(57.4)$

157 (42.5)

Blood group

A

B

O

AB

Hypertension (HTN)

No

Yes

Diabetes mellitus (DM)

No

Yes

Ischemic heart disease (IHD)

No

Yes

Lung disease

No

Yes

Chronic kidney disease (CKD)

No

Yes

Disease severity

No

Yes

Hemoglobin level $(\mathrm{Hb})$, mean $\pm \mathrm{SD}$
81 (21.9)

147 (39.8)

$111(30.0)$

30 (8.1)

$226(61.2)$

$143(38.7)$

$233(63.1)$

$136(36.8)$

$313(84.8)$

$56(15.1)$

348 (94.3)

$21(5.6)$

332 (89.9)

$37(10.0)$

$258(69.9)$

$111(30.0)$

$11.7 \pm 2.6$

TABLE 1: Basic characteristics of study participants $(\mathrm{N}=369)$.

All independent variables were considered for their potential association with disease severity in univariate analysis using logistic regression for which unadjusted Odds Ratios were calculated. Age, gender, hypertension, diabetes mellitus, and hemoglobin level, were all associated with disease severity among COVID-19 patients in univariate analysis on P-value for selection $(<0.05)$ as mentioned in Table 2 


\section{Cureus}

\begin{tabular}{|c|c|c|}
\hline Characteristics & OR $(95 \% \mathrm{Cl})$ & P-value \\
\hline Age (years) & $1.04(1.02-1.05)$ & $<0.001^{*}$ \\
\hline \multicolumn{3}{|l|}{ Gender } \\
\hline Males & $3.85(2.30-6.44)$ & $<0.001^{\star}$ \\
\hline Females & - & \\
\hline \multicolumn{3}{|l|}{ Blood group } \\
\hline A & $1.11(0.60-2.07)$ & \\
\hline B & $0.88(0.51-1.52)$ & 0.55 \\
\hline $\mathrm{O}$ & $1.57(0.68-3.63)$ & \\
\hline AB & - & \\
\hline \multicolumn{3}{|l|}{ Hypertension (HTN) } \\
\hline No & - & \\
\hline Yes & $1.61(1.02-2.54)$ & $0.037^{\star}$ \\
\hline \multicolumn{3}{|l|}{ Diabetes mellitus (DM) } \\
\hline No & - & \\
\hline Yes & $1.91(1.22-3.03)$ & $0.004^{\star}$ \\
\hline \multicolumn{3}{|c|}{ Ischemic heart disease (IHD) } \\
\hline No & - & \\
\hline Yes & $1.94(1.08-3.49)$ & 0.027 \\
\hline \multicolumn{3}{|l|}{ Lung disease } \\
\hline No & - & \\
\hline Yes & $1.46(0.58-3.63)$ & 0.419 \\
\hline \multicolumn{3}{|c|}{ Chronic kidney disease (CKD) } \\
\hline No & - & \\
\hline Yes & $0.72(0.33-1.59)$ & 0.412 \\
\hline Hemoglobin level (Hb) & $1.15(1.05-1.27)$ & $0.001^{*}$ \\
\hline
\end{tabular}

TABLE 2: Univariate analysis of factors associated with disease severity among COVID-19 patients of Karachi, Pakistan ( $\mathrm{N}=369$ ).

OR, odds ratio; $\mathrm{Cl}$, confidence interval. ${ }^{*} \mathrm{P}$-value of $\leq 0.05$ was considered statistically significant.

The findings from multiple logistic regression models are given in Table 3, examining the association between disease severity and the blood group. The final model showed that the odds of disease severity among male patients are 3.62 times greater than female patients (OR: 3.62, 95\% CI: 2.15-6.08). Moreover, the odds of disease severity are 2.00 times higher among diabetic patients than non-diabetic patients (OR: 2.00, 95\% CI: 1.10-3.01). However, there was no significant association found between blood group and disease severity among COVID-19 patients. 


\section{Cureus}

\begin{tabular}{|c|c|c|}
\hline Characteristics & OR (95\% CI) & P-value \\
\hline \multicolumn{3}{|l|}{ Gender } \\
\hline Males & $3.62(2.15-6.08)$ & $<0.001^{\star}$ \\
\hline Females & - & \\
\hline \multicolumn{3}{|l|}{ Blood group } \\
\hline $\mathrm{A}$ & $1.18(0.61-2.26)$ & 0.611 \\
\hline B & $0.86(0.48-1.53)$ & 0.615 \\
\hline 0 & - & - \\
\hline$A B$ & $1.48(0.61-3.58)$ & 0.380 \\
\hline \multicolumn{3}{|c|}{ Diabetes mellitus (DM) } \\
\hline No & - & \\
\hline Yes & $2.00(1.10-3.01)$ & $0.018^{\star}$ \\
\hline
\end{tabular}

\section{TABLE 3: Multivariable analysis of factors associated with disease severity among COVID-19}

patients of Karachi, Pakistan ( $\mathrm{N}=369$ ).

${ }^{*} \mathrm{P}$-value of $\leq 0.05$ was considered statistically significant.

\section{Discussion}

In this observational study, we found that COVID-19 disease severity is not associated with any of the ABO blood group types, and the same observations were also found in other studies $[9,10]$. However, in several studies, it has been found that people with blood A suffer more severe disease as compared to the individual with blood group $\mathrm{O}[11,12]$. The proposed mechanism for higher disease severity in the individual with blood group A includes its positive association with angiotensin-converting enzyme activity and higher expression of adhesion molecules which in turn increase inflammation and hinders circulation [11].

Zhao et al. found that $\mathrm{ABO}$ blood groups play role in predisposing the people with blood group $\mathrm{A}$ to acquire the disease as opposed to the individual with blood group O [13], but in our study, the blood group B people were predominant that is $39.8 \%$ while people from group A were $21 \%$ only. The possible reason could be that we included only those patients whose blood groups were already known for some other reasons like blood donation and the different ethnicity of our study population as it does have a role in ABO blood typing [14]. Moreover, almost one-third of our study participants were having a non-severe disease (69.9\%) while only $21.9 \%$ had severe disease.

Male gender was strongly correlated with disease severity in our study population, congruent to already established evidence [15]. The factors responsible for less severe disease in females include their lower proneness to disease as they are equipped with two copies of the $\mathrm{X}$ chromosome which bears the genes involved in the regulation of innate immunity. They also have higher expression toll-like receptors-7 (TLR7) and CD4+ lymphocytes which play a key role in the defense against viral infection and the clearance of viruses respectively [16].

We also found that diabetic patients were having more severe COVID-19 disease as compared to their counterparts [17]; possible reasons include the metabolic changes in diabetic patients, chronic inflammation, attenuation of both innate and adaptive immune responses predisposing to secondary infection [18]. Moreover, diabetic patients have a higher expression of angiotensin-converting enzyme 2, which facilitates viral uptake thereby increase chances of having severe disease than non-diabetic patients $[19,20]$.

The findings of our study are important; however, it was a small observation single-center study, so the findings can't be generalized. Studies conducted in multiple centers on diverse populations will help in establishing the relationship of ABO blood groups with COVID-19 disease severity

\section{Conclusions}

We found no association between blood groups and COVID-19 disease severity. However, male gender and 
diabetes mellitus were strongly associated with disease severity, warranting more vigilant care.

\section{Additional Information Disclosures}

Human subjects: Consent was obtained or waived by all participants in this study. The Aga Khan University Hospital, Karachi, Pakistan issued approval ERC\#2020-5277-11810. Dear Dr. Fazal Rehman, 2020-527711810. Fazal Rehman: THE ASSOCIATION OF BLOOD GROUP WITH THE SUSCEPTIBILITY AND SEVERITY OF CORONAVIRUS DISEASE: A CROSS-SECTIONAL STUDY FROM A TERTIARY CARE HOSPITAL KARACHI. Thank you for your application for exemption from ethical approval regarding the above-mentioned study. Your study was reviewed and approved as exemption. Please ensure that the study is performed as per protocol following all AKU standards. . Animal subjects: All authors have confirmed that this study did not involve animal subjects or tissue. Conflicts of interest: In compliance with the ICMJE uniform disclosure form, all authors declare the following: Payment/services info: All authors have declared that no financial support was received from any organization for the submitted work. Financial relationships: All authors have declared that they have no financial relationships at present or within the previous three years with any organizations that might have an interest in the submitted work. Other relationships: All authors have declared that there are no other relationships or activities that could appear to have influenced the submitted work.

\section{References}

1. Lu H, Stratton CW, Tang YW: Outbreak of pneumonia of unknown etiology in Wuhan, China: the mystery and the miracle. J Med Virol. 2020, 92:401-2. 10.1002/jmv.25678

2. Singh TK, Kumar S, Tiwari P. Review on COVID-19 (coronavirus disease) . (2020). Accessed: 27 March 2021: https://www.pharmatutor.org/articles/review-on-covid-19-corona-virus-disease.

3. Chen N, Zhou M, Dong X, et al.: Epidemiological and clinical characteristics of 99 cases of 2019 novel coronavirus pneumonia in Wuhan, China: a descriptive study. Lancet. 2020, 395:507-13. 10.1016/S01406736(20)30211-7

4. Batool Z, Durrani SH, Tariq S: Association of ABO and Rh blood group types to hepatitis B, hepatitis C, HIV and syphilis infection, a five year' experience in healthy blood donors in a tertiary care hospital. J Ayub Med Coll Abbottabad. 2017, 29:90-2.

5. Lindesmith L, Moe C, Marionneau S, et al.: Human susceptibility and resistance to Norwalk virus infection . Nat Med. 2003, 9:548-53. 10.1038/nm860

6. Cheng Y, Cheng G, Chui $\mathrm{CH}$, et al.: ABO blood group and susceptibility to severe acute respiratory syndrome . JAMA. 2005, 293:1450-1. 10.1001/jama.293.12.1450-c

7. Wu O, Bayoumi N, Vickers MA, Clark P: $\mathrm{ABO}(\mathrm{H})$ blood groups and vascular disease: a systematic review and meta-analysis. J Thromb Haemost. 2008, 6:62-9. 10.1111/j.1538-7836.2007.02818.x

8. Maguire BJ, Guérin PJ: A living systematic review protocol for COVID-19 clinical trial registrations . Wellcome Open Res. 2020, 5:60. 10.12688/wellcomeopenres.15821.1

9. Latz CA, DeCarlo C, Boitano L, et al.: Blood type and outcomes in patients with COVID-19. Ann Hematol. 2020, 99:2113-8. 10.1007/s00277-020-04169-1

10. Liumbruno GM, Franchini M: Beyond immunohaematology: the role of the ABO blood group in human diseases. Blood Transfus. 2013, 11:491-9. 10.2450/2013.0152-13

11. Dai X: ABO blood group predisposes to COVID-19 severity and cardiovascular diseases . Eur J Prev Cardiol. 2020, $27: 1436-7.10 .1177 / 2047487320922370$

12. Hoiland RL, Fergusson NA, Mitra AR, et al.: The association of ABO blood group with indices of disease severity and multiorgan dysfunction in COVID-19. Blood Adv. 2020, 4:4981-9. 10.1182/bloodadvances.2020002623

13. Fan Q, Zhang W, Li B, Li DJ, Zhang J, Zhao F: Association Between ABO Blood Group System and COVID-19 Susceptibility in Wuhan. Front Cell Infect Microbiol. 2020, 10:404. 10.3389/fcimb.2020.00404

14. Garratty G, Glynn SA, McEntire R: $A B O$ and $\mathrm{Rh}(\mathrm{D})$ phenotype frequencies of different racial/ethnic groups in the United States. Transfusion. 2004, 44:703-6. 10.1111/j.1537-2995.2004.03338.x

15. Jin JM, Bai P, He W, et al.: Gender differences in patients with COVID-19: focus on severity and mortality . Front Public Health. 2020, 8:152. 10.3389/fpubh.2020.00152

16. Conti P, Younes A: Coronavirus COV-19/SARS-CoV-2 affects women less than men: clinical response to viral infection. J Biol Regul Homeost Agents. 2020, 34:339-43. 10.23812/Editorial-Conti-3

17. Kumar A, Arora A, Sharma P, et al.: Is diabetes mellitus associated with mortality and severity of COVID-19? A meta-analysis. Diabetes Metab Syndr. 2020, 14:535-45. 10.1016/j.dsx.2020.04.044

18. Toniolo A, Cassani G, Puggioni A, Rossi A, Colombo A, Onodera T, Ferrannini E: The diabetes pandemic and associated infections: suggestions for clinical microbiology. Rev Med Microbiol. 2019, 30:1-17. 10.1097/MRM.0000000000000155

19. Lu R, Zhao X, Li J, et al.: Genomic characterisation and epidemiology of 2019 novel coronavirus: implications for virus origins and receptor binding. Lancet. 2020, 395:565-74. 10.1016/S01406736(20)30251-8

20. Zhang H, Penninger JM, Li Y, Zhong N, Slutsky AS: Angiotensin-converting enzyme 2 (ACE2) as a SARSCoV-2 receptor: molecular mechanisms and potential therapeutic target. Intensive Care Med. 2020, 46:58690. 10.1007/s00134-020-05985-9 